\title{
Psicoterapia Psicanalítica e Acompanhamento Terapêutico: \\ uma Aliança de Trabalho
}

Psychoanalytical psychotherapy and therapeutical accompaniment: a partnership

Resumo: O objetivo do artigo é refletir sobre a possibilidade de formação de uma aliança de trabalho entre psicoterapia psicanalítica e outras práticas psicoterápicas no atendimento a pacientes com psicopatologias

Helga

de Souza

Machado

Quagliatto

Psicóloga clínica Mestre em Educação Magistério Superior pelo Centro Universitário do Triângulo (UNIT), diretora de estudos do CEEPU (Centro de Estudos e Eventos Psicanalíticos de Uberlândia).

Ricardo Gomides Santos

Psicólogo clínico, acompanhante terapêutico e mestrando em Psicologia Social pela Universidade de São Paulo (USP).

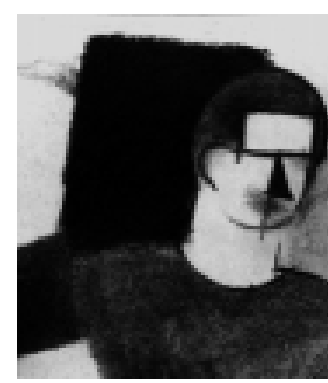
graves. Apresentamos o caso clínico de um adolescente borderline que, em função do surto psicótico, tem seu tratamento reformulado, passando a contar com um acompanhante terapêutico. A aliança de trabalho formada busca envidar esforços clínicos na mesma direção: a promoção da qualidade de vida mental e social do paciente. Por fim, desenvolvemos algumas considerações sobre os ganhos psicoterapêuticos de uma postura inovadora e interdisciplinar, bem como sobre as particularidades de cada atendimento clínico.

Palavras-Chave: Psicoterapia, acompanhamento terapêutico, psicopatologia, Psicanálise.

Abstract:The purpose of this paper is to take into account the possibility of developing a work partnership between psychoanalytical psychotherapy and other psychotherapeutical procedures, aiming at the treatment of patients suffering from serious psychopathologies. A borderline teenager patient is presented as a case, in which a psychotic episode has led to a reformulation of the treatment, including therapeutic accompaniment. The goal of this partnership is to combine clinical efforts that can bring more quality to the patient's mental and social life. Finally, we focus on the psychotherapeutical benefits resulting from an innovative, interdisciplinary approach and some particularities of the clinical case.

Key Words: Psychotherapy, therapeutical accompaniment, psychopathologie,Psychoanalysis.

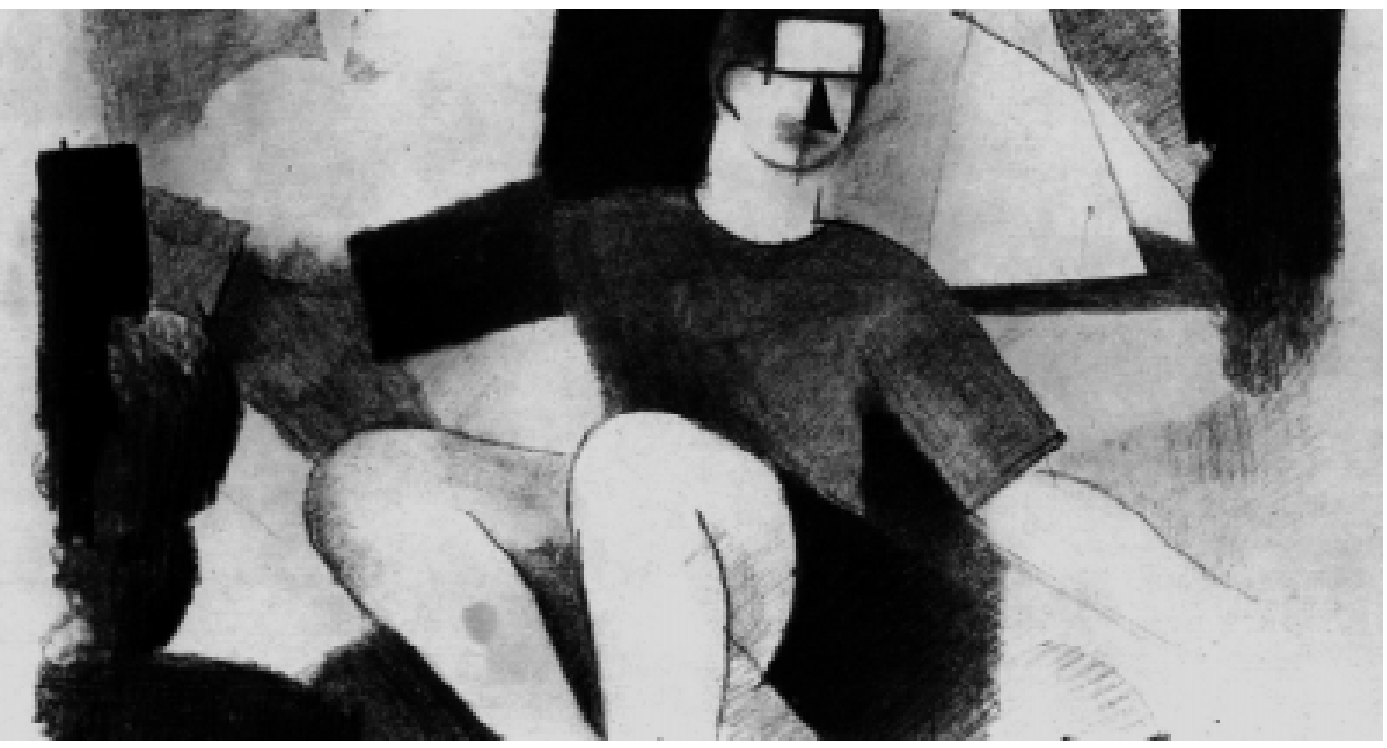

Ao analisar o desenvolvimento da Psicanálise para conceber e particularizar um método de investigação da psique humana, uma teoria sobre o seu funcionamento e uma técnica terapêutica, é possível observar um aprimoramento clínico relacionado ao atendimento e à compreensão das psicopatologias graves.

Tal aprimoramento é fruto de décadas de trabalho, no qual se destaca, inicialmente, a valorização de Klein (1982) ao desenvolvimento emocional primitivo, com ênfase nas relações objetais internalizadas e, contemporaneamente, a interação entre distintas ciências e modalidades terapêuticas no atendimento a esses pacientes.

Em nosso trabalho, iremos abordar, para um diálogo reflexivo, uma dessas possibilidades de aliança, ou seja, a relação entre psicoterapia psicanalítica e acompanhamento terapêutico, como resultado de uma intervenção clínica organizada para auxiliar-nos em uma situação específica: a irrupção de um surto psicótico. 


\section{O Manejo Clínico de Pacientes com Patologias Graves}

Várias contribuições geraram modificação no manejo da técnica psicoterápica de determinados pacientes, em especial aqueles caracterizados por Zimerman (1998) como portadores de patologias graves:" psicóticos, borderlines, transtornos narcisistas, perversos, drogaditos, psicopatas, melancólicos crônicos, pacientes impulsivos, os marcadamente psicossomatizadores e os casos de neuroses que abrigam fortes e ativos núcleos psicóticos"( p. 747).

Os trabalhos desenvolvidos, especificamente com psicóticos, demandaram a formulação de proposições teóricas capazes de lançar luzes sobre suas características de funcionamento mental, angústias, fantasias inconscientes e mecanismos de defesa, bem como sobre as peculiaridades do vínculo transferencial estabelecido.

Tornou-se também importante o aprimoramento da capacidade diagnóstica dos profissionais, pois tal procedimento passou a ser vislumbrado, em Psicanálise, como a possibilidade de se estabelecer uma primeira compreensão a respeito da estrutura psíquica da pessoa entrevistada, não estando mais o diagnóstico restrito à classificação nosográfica das doenças mentais.

Hermann (1993) declara que o nosso objetivo não é fazer um diagnóstico psiquiátrico,

“... mesmo porque a maior parte das pessoas que nos procuram, felizmente, não se enquadra em nenhum deles, sequer são neuróticos estruturados. Basta não deixar de fazê-lo quando este se impõe. No mais, contentamo-nos com o diagnóstico transferencial. Cuidado, porém. O diagnóstico transferencial deve pôr em evidência a absoluta especificidade da vida do paciente, seu sentido vivo" (p.57).

Sendo assim, deparamo-nos com uma amplitude de variáveis presentes na avaliação e caracterização do que se conhece por pacientes com psicopatologias graves e, dependendo dos critérios adotados pelo profissional ${ }^{1}$, diferentes particularidades serão observadas no processo de formação do diagnóstico e prognóstico clínico, o que levará à adoção de posturas técnicas diferenciadas.

A paulatina descoberta da "especificidade da vida" do paciente deve ser acompanhada da atenção a uma série de fatores que dizem respeito às possibilidades do vínculo em formação vir a efetivar, de fato, um processo psicoterapêutico.
Acreditamos que, no atendimento clínico aos portadores de psicopatologias graves, tal processo passa pelo que Cassorla (1998) denominou "impasse necessário". Para esse autor, mesmo a relação transferencial sendo estabelecida e interpretada, e por melhor que a psicoterapia seja conduzida, haveria momentos em que o processo sofreria um impasse em função da violência e do uso de identificações projetivas maciças que dificultam o pensar analítico. Esses momentos ocorreriam em todas as relações com tais pacientes, caracterizando, então, como necessário, o impasse surgido nessa modalidade clínica.

A dificuldade no atendimento também foi abordada por Winnicott (1982) quando destaca que, na relação analítica com pacientes psicóticos, intervém a presença constante de um ódio contratransferencial: "... ainda que o analista ame seus pacientes, ele não pode evitar odiá-los e temêlos e, quanto melhor ele souber disto, menos o ódio e o temor determinarão suas ações sobre os pacientes" (p. 342).

O entendimento da dinâmica transferencial e contratransferencial, própria a esses casos, é um esteio fundamental na tolerância aos ataques feitos ao vínculo e à pessoa real do psicoterapeuta, ainda que isso possa levar a dupla a ingressar em um "impasse necessário" na medida em que este puder ser visto como uma oportunidade de revitalização dos potenciais de ambos para continuar empreendendo a psicoterapia.

Sendo assim, o "impasse necessário" pode levar a uma interrupção da relação psicoterapêutica com duração possível de minutos a meses, pois, segundo Cassorla (1998): “... a Psicanálise pode não ser suficiente para controlar a explosão psicótica" (p. 730) e ainda obriga os profissionais a “... rever os procedimentos estandardizados da Psicanálise, quando são compreendidos de forma rígida" (p. 724).

Diante do surto e do ingresso no "impasse necessário", Cassorla (1998) propõe ainda uma postura de maior autonomia por parte do psicoterapeuta, que "... deve sentir-se livre para usar qualquer procedimento (mesmo não analítico), se sua experiência mostrar que isso lhe é útil, mas ele deve saber nomear e conceituar o que está fazendo"( p. 732).

Se a relação transferencial permite a formulação de um diagnóstico que é a apreensão viva do modo como cada pessoa se singularizou, tal como nos diz Herrmann (1993), a postura humilde, criativa e metodologicamente orientada do psicoterapeuta possibilita o desenvolvimento de formas também singulares de atendimento às demandas de seus
1 Os critérios citados podem ser os da psicopatologia clássica, com o exame das funções psiquicas, ou os da Psicanálise, com a observação da relação transferencial estabelecida e das defesas psíquicas postas em ação pelo paciente. 
pacientes, o que é especialmente necessário e até mesmo exigido quando tais pacientes sofrem de patologias graves. Tal especificidade explica-se pelo visto até agora: as características do vínculo transferencial no qual se impõem sentimentos de ódio, ataques à relação e o ingresso no "impasse necessário".

Uma das possibilidades técnicas de intervenção, com a finalidade de superar o impasse necessário, provendo os cuidados essenciais à saúde mental e, muitas vezes, saúde física do paciente, poderia ser a formação de parcerias com outros ramos do saber e com outras modalidades de trabalho.

Para ilustrar tais idéias, apresentaremos o caso clínico de um adolescente borderline, em que a irrupção de um surto psicótico suscitou a vivência de um impasse no trabalho, uma vez que os intensos ataques ao vínculo transferencial demandaram a reformulação técnica de seu tratamento.

\section{Discussão clínica}

Antes de passarmos diretamente à apresentação clínica do caso, faremos uma breve explanação teórica sobre o ingresso de um paciente em um estado de crise psicótica, caracterizando as peculiaridades de seu acompanhamento.

Estar com um paciente em estado psicótico é acompanhar uma relativa adaptação ao mundo externo, pois entramos em contato com um universo de emoções e fantasias arcaicas que oscilam da total fragilidade e dependência à extrema arrogância e triunfo. Nesse estado, é como se esses dois universos não se reconhecessem, impedindo a integração do mundo mental e, justamente por ser um estado, vale lembrar que o surto psicótico é passageiro e o paciente pode se recuperar.

Nesse estado, o paciente vive uma desorganização de suas funções egóicas, dentre as quais sua capacidade de percepção da realidade, tanto interna quanto externa. Nos dizeres de Bion (1988), passam a ocorrer "ataques ao aparelho de pensar", impedindo o sujeito, sob o domínio da parte psicótica da personalidade, de entrar em contato com uma realidade considerada insuportável. Decorre desse ataque o ingresso do paciente em um estado de confusão mental em que os vínculos interpessoais se esgarçam e as pessoas significativas, bem como os objetos da realidade, passam a ser investidos de conteúdos fantasísticos geralmente de caráter persecutório e ameaçador.
Podem surgir, então, comportamentos de violência direcionada às pessoas próximas e a ele mesmo, $\mathrm{o}$ que gera intenso sofrimento. A expressão da violência torna-se uma forma de livrar-se dos objetos internos maus e persecutórios, levando o paciente a atuações com vista à evacuação das intensas angústias, sentidas como angústias de aniquilamento: seja de sua condição mental, seja de seu próprio corpo.

Enquanto o psicoterapeuta tem possibilidade de acompanhar, observar e investigar as oscilações e os fenômenos mentais advindos da personalidade psicótica, é possível tocar em um universo na presença do outro, tendo a transferência e a contratransferência como aliados.

Entretanto, ocorrem momentos em que um desses universos se apossa da personalidade do indivíduo, seja por fatores externos, em comunhão com fatores internos, conhecidos ou desconhecidos, processo esse que pode estar ou não vinculado à psicoterapia. Nessas circunstâncias, a conjunção de fatores externos e internos mediados pela parte psicótica da personalidade pode levar o paciente a se defrontar com situações mobilizadoras de intensa ansiedade, levando-o a sentir-se ameaçado em sua integridade física e mental. Nesses momentos, irrompe a "crise psicótica" e a vida real fica em perigo, pois um universo não mais protege o outro.

Renato é um jovem que, na ocasião, estava em psicoterapia há cerca de 01 ano e apresentava uma evolução no sentido de maior contato entre mundo interno e mundo externo. Durante um fim de semana, dificuldades nas relações bipessoais e triangulares colocaram Renato frente a situações de humilhação, incompreensão, desproteção, acompanhadas de castigos. A autoridade prevalecia por meio da violência e imposição rígidas. Não suportando a realidade por demais frustrante e não encontrando acolhimento para suas angústias, tenta matar-se como forma de livrarse dos maus objetos.

O perigo posto à vida real do paciente demonstra a falência de seus recursos mentais mínimos de continência às ansiedades e ao sentimento de desamparo vividos no estado de crise. Esse terror sem nome ${ }^{2}$ ganha corpo por encontrar justamente no próprio corpo a via expressiva da potência destrutiva que a mente do paciente não pode mais conter. Seja voltada para ele próprio (tentativas de suicídio), seja voltada para os outros (figuras depositárias de identificações projetivas), a crise psicótica, com todo seu terror, ameaça e faz eclodir a violência das fantasias persecutórias e de morte próprias ao mundo mental do paciente, colocando em risco sua vida e a sobrevivência dos vínculos interpessoais. 
Nos seus espaços de convivência, Renato não tolera nenhum tipo de frustração e as tentativas de eliminar os objetos persecutórios, internos e externos, passam a ser freqüentes.

Na psicoterapia, o mesmo movimento é vivido na relação transferencial. Caso ocorresse uma possibilidade de frustração, mesmo fantasiada, o objetivo era destruir o objeto perseguidor de forma sádica e violenta. O vínculo anterior também não era mais reconhecido, gerando terríveis angústias contratransferenciais.

Nesses momentos, é preciso recorrer a outras possibilidades para que o psicoterapeuta não se sinta sem recursos ou acorrentado pelo "nãomundo", pela "não-vida", "não-tempo", "nãolinguagem simbólica". Um psiquiatra foi indicado e o mesmo ministrou uma medicação, na busca desse reencontro.

Os sentimentos contratransferenciais nas sessões eram de medo, dor, ódio, desamparo e solidão. Os ataques verbais e emocionais eram contínuos, mesmo com a medicação.

Em uma sessão, a situação se concretiza. Renato chega ao consultório e, ao entrar, recusa-se a ir para sua sala de costume, dirigindo-se à sala de atendimento de adultos. Deita-se no divã, paralisado. É então questionado sobre o que queria na sala de adultos. Com o olhar transfigurado, sudorese e intensa salivação, diz que irá fazer com a psicoterapeuta o que os adultos fazem com ele e parte para agredi-la fisicamente. Sua força era imensa, e, em meio ao medo e a um profundo sentimento de desproteção e solidão, com a voz o mais firme e no tom o mais alto que fora possível dentro daquela condição, interrompeu-se o atendimento, dizendo-se-Ihe mais ou menos o seguinte, de acordo com o que a memória ainda permite registrar: "Que se ele conseguisse me machucar, ficaria ainda mais assustado e que dessa forma não poderíamos estar mais juntos... retomaríamos somente quando pudéssemos ficar sem nos machucarmos". Livrando as mãos com dificuldade, foi aberta a porta da sala de espera, comunicando à pessoa que o conduzira à sessão que os atendimentos estavam suspensos por tempo indeterminado. Ele olha e parece que o seu olhar se diferencia, algo se havia rompido. Naquele momento, sente-se que nada mais poderia ser dito, palavras pareciam sofisticadas demais frente a angústias tão intensas e primitivas.

Eram angústias de morte, de aniquilamento.

A familiaridade com seu próprio ódio faz com que o psicoterapeuta seja capaz de conter o ódio de seu paciente, sem atacá-lo ou esperar que ele reconheça o esforço dispendido em seu tratamento. Nesses casos, diz-nos novamente Winnicott (1982), o psicoterapeuta funcionaria como a mãe de um bebê não nascido ou recémnascido. A importância da adoção dessa postura justifica-se pelo fato de que, provavelmente, o psicoterapeuta seria "... a primeira pessoa na vida do paciente a fornecer certas coisas que são essenciais no meio ambiente" (p. 347).

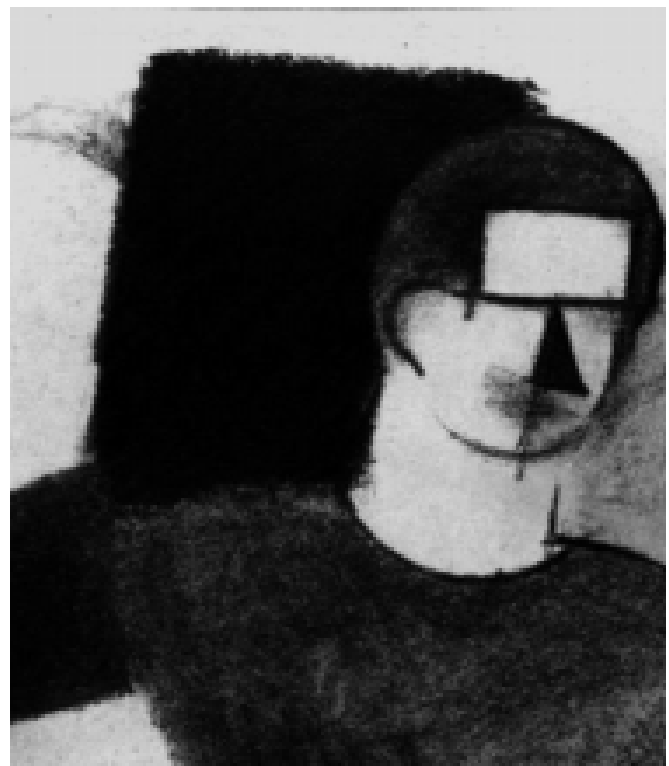

Em seu estado de confusão mental, sem o reconhecimento do vínculo anteriormente estabelecido, Renato vem à sessão transtornado por seus objetos internos persecutórios e atua de modo destrutivo seu drama pessoal de violência e desrespeito. A intensidade com que o ódio foi sentido objetivamente pela psicoterapeuta e sua reação a ele permitiram a Renato reconhecer a força e a violência de seus atos. A psicoterapeuta reagiu como ele próprio não consegue, protegendo-se dos ataques feitos à sua condição física e mental e, para além dessa reação, conseguiu dar-lhe a medida dos sentimentos que provocava: ódio, desamparo e medo. De uma maneira objetiva, em meio à sua confusão, Renato foi pego de surpresa com o reconhecimento de sua própria violência e das conseqüências que esta poderia trazer: ferir quem lhe é tão importante.

O colapso das funções egóicas mais desenvolvidas e a irrupção do estado de crise psicótica torna-se a expressão da violência contida no universo mental do paciente e permite ao psicoterapeuta considerar suas atuações como uma forma de comunicação primitiva capaz de manifestar, ainda que por vias destrutivas, os aspectos terroríficos de seu mundo interno esparramados sobre a realidade via identificação projetiva patológica. O uso maciço desse mecanismo de defesa termina por gerar o
"Que se ele conseguisse me machucar, ficaria ainda mais assustado e que dessa forma não poderíamos estar mais juntos. retomaríamos somente quando pudéssemos ficar sem nos machucarmos".

No atendimento a psicóticos há situações em que se torna necessário tentar promover o manejo adequado dos pacientes fora das sessões, criando o suporte para a realização do trabalho psicoterapêutico. Segal (1982) nos chama a atenção para esse fato: “... o paciente tem que viver entre as sessóes e pelo menos suas necessidades mínimas têm que ser. satisfeitas" (p. 181)

4 Esse termo é proposto por François Roustang (1987) refere-se ao processo de expropriação-lastração engendrado na inter-relação entre uma das figuras parentais e a criança. Por meio desse processo, a figura parental expropriante se apropriaria dos atos, palavras e até dos pensamentos das crianças, fazendo com que estas passassem a relacionar-se não com produções e pensamentos próprios, mas com as lastrações advindas da expropriação ocorrida. 
que Bion (1988) denominou "objetos bizarros", que são os objetos com os quais o paciente psicótico se relaciona nos momentos de crise e o impedem de reconhecer tanto os antigos vínculos pessoais quanto seus ambientes de vida.

Com a postura de autoridade e a imposição firme de um limite para o convívio seguro de ambos, Renato teve a oportunidade de se relacionar com um adulto que age de modo diferente daqueles que compõem seu universo mental: a violência e o ódio não foram retribuídos, mas contidos da única maneira possível àquele momento. Os atendimentos foram interrompidos como forma de se preservar o vínculo de maiores violências. Renato não se sentiu atacado, mas protegido de sua própria destrutividade. A psicoterapeuta deuIhe mostras concretas, não fantasiosas, de sua violência e seus efeitos nocivos. Notar tais aspectos talvez tenha permitido uma reorganização mínima de Renato que, mesmo sem contar com os atendimentos psicoterapêuticos, pôde retomar uma organização egóica capaz de protegê-lo dos ataques contra si mesmo.

\section{"O problema, para o terapeuta, é manter o equilíbrio entre aproximar-se \\ suficientemente do paciente para permanecer em contato - o que com crianças muito \\ perturbadas pode implicar séria inquietação e \\ preocupação, raíva e desespero - e ficar afastado o suficiente para ser capaz de pensar"}

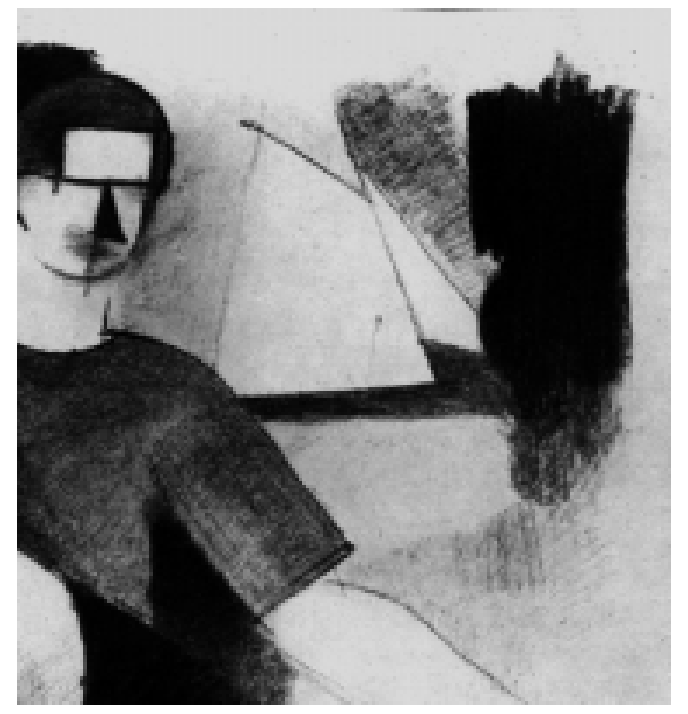

Alvarez (1994) diz o seguinte:

"O problema, para o terapeuta, é manter o equilíbrio entre aproximar-se suficientemente do paciente para permanecer em contato - o que com crianças muito perturbadas pode implicar séria inquietação e preocupação, raiva e desespero - e ficar afastado o suficiente para ser capaz de pensar. Não conheço ninguém que consiga manter este equilíbrio no nível adequado durante todo o tempo" (p.18)

No período de afastamento, pensamos muito no que foi sentido e vivido com Renato. Pensamos em nunca mais vê-lo, pensamos em proteção, mas também na solidão, no medo, na morte. Compreendemos que era assim que ele se sentia frente aos objetos persecutórios reais e imaginados. Aspectos contratransferenciais de ódio norteavam os pensamentos relacionados ao vínculo psicoterapêutico tão violentamente atacado e a intensidade de tais sentimentos impossibilitavam sua interpretação ou mesmo a retomada do convívio mútuo.

Acompanhamos a família, estabelecendo dessa forma um elo de ligação com o paciente, mesmo à distância. Percebemos que os pais também se encontravam desprotegidos frente às ameaças de morte, ficando impossibilitados de colaborar para a qualidade mental do filho. Reavaliamos também, junto ao psiquiatra, a medicação.

Acreditamos que, frente às situações de "impasse", é necessária uma atitude realística para se examinar a situação transferencial e contratransferencial. Passaram-se mais de trinta dias de afastamento e recebíamos notícias, através dos familiares, de um reconhecimento da perda do vínculo psicoterapêutico pelo paciente.

Sentíamos que não seria possível abandoná-lo, mas seria preciso criar alternativas que não fossem rígidas ou onipotentes (teórica e pessoalmente) para a condução de seu tratamento. Passamos a vê-lo, a seu pedido, ocasionalmente. Foi então que pudemos perceber que a companhia da psicoterapeuta era insuficiente naquele dado momento, frente as suas reais necessidades. No seu cotidiano, a família, transtornada, não conseguia apresentar atitudes realísticas e não retaliadoras às dificuldades de Renato. Ele precisava de mais uma "companhia viva", alguém que estivesse presente no seu dia a dia, que o acompanhasse concretamente nos momentos domiciliares de desamparo e desproteção. Ele estava profundamente sozinho e a morte era a única alternativa que se lhe apresentava como companhia $^{3}$.

Situações difíceis como a relatada, em que os sentimentos são muitos e, por vezes, contraditórios, têm ressonância por um longo tempo e remontam à força emocional surgida no campo transferencial. Herrmann (2000), investigando a complexa estrutura do processo analítico, distingue três tempos simultâneos na análise, que não se esgotam ou se dão unicamente durante os atendimentos. O "tempo curto" é o tempo da própria sessão, com as intervenções do psicoterapeuta e as falas do paciente; o "tempo médio" é o tempo dos sentimentos transferenciais em que o psicoterapeuta “... pega em suas mãos o sofrimento do paciente, ou, a rigor, o recebe no próprio coração, tempo que transcende o horário de 
sessão"; já o "tempo longo" é o tempo “... do destino do paciente, que procede da história de sua infância, de seus pais, de sua gente" (p.433).

Intervindo em meio ao "tempo médio", a psicoterapeuta buscou auxiliar a família durante o "impasse necessário" e, contratransferencialmente, compreendeu como o paciente estaria sentindo-se. Do mesmo modo, o paciente, pela transferência, deu mostras de ressentir-se da interrupção dos atendimentos durante o impasse.

Renato necessitava de mais uma "companhia", mas não poderia ser qualquer "companhia", teria que ser alguém vivo, disponível, acessível e com quem Renato pudesse identificar-se, ou melhor, agarrar. Renato necessitava experenciar um outro modo de estar em contato com um adulto, uma pessoa que tivesse verdadeira disposição em estar a seu lado, não repetindo as atitudes expropriantes ${ }^{4}$ características de seus vínculos familiares. Renato necessitava de uma pessoa capaz de ser criança com ele para, em companhia de um outro ao seu lado, retomar o curso de sua adolescência, enfrentando as já difíceis imposições psíquicas desse período de vida.

Alvarez (1994) descreve que, para ocorrer o desenvolvimento emocional e cognitivo, "... o bebê precisa ter a experiência de interagir com um cuidador humano consistente, um objeto animado, ou, na expressão de Trevarthen, uma companhia viva" ( p.88).

Foi então que surgiu a idéia de um acompanhante terapêutico (AT), alguém que, em seu domicílio, pudesse auxiliá-lo em suas funções de ego, promovendo um contato com o mundo de forma menos arriscada.

\section{O Acompanhamento Terapêutico}

O trabalho de acompanhamento terapêutico surgiu como forma complementar às intervenções psicoterapêuticas tradicionais de atendimento a pacientes psicóticos: psicoterapia, uso de medicamentos psiquiátricos e, em alguns casos, internação psiquiátrica. Mauer \& Resnizky (1987) propõem a inclusão do acompanhante terapêutico (AT) como integrante de uma "equipe terapêutica" que adote abordagens múltiplas no atendimento a esses pacientes.

Carrozzo (2001) propõe a tese de que uma abordagem isolada não sustenta o tratamento do fragmentário da psicose, demandando a formação de uma rede de atendimento na qual atuariam "... o psiquiatra, o remédio, o psicanalista, os terapeutas do hospital-dia e os acompanhantes terapêuticos"( p. 12). Caberia aos últimos ampliar o atendimento para todos os locais onde o "acontecer humano" pode dar-se, utilizando recortes do cotidiano como ferramenta psicoterapêutica.

Uma das justificativas para a inclusão dessa outra prática psicoterapêutica relaciona-se à necessidade de acompanhar o paciente em seus vários espaços de vida, especialmente nos momentos de crise, em que a família não mais tem recursos afetivos e psíquicos para acolher e conter a desorganização mental do paciente.

Dentre as funções desempenhadas pelo acompanhante terapêutico, Mauer \& Resnizky (1987) destacam: a continência afetiva às angústias do paciente, especialmente em momentos de crise, a possibilidade de o AT ser tomado como modelo de identificação, o emprego das funções egóicas do AT em atenção às dificuldades do paciente, o desenvolvimento das capacidades criativas do paciente, respeitando suas peculiaridades, atenção e respeito ao mundo objetivo, que passaria a ser compartilhado pelo AT e pelo paciente, representação do psicoterapeuta, sendo ele uma outra pessoa em atenção à sua saúde mental, atuação como agente ressocializador e auxílio nas relações familiares, geralmente esgarçadas pela crise psicótica.

Em nosso caso, o acompanhamento terapêutico surgiu como recurso técnico complementar àqueles já oferecidos ao paciente, vindo a somar esforços clínicos em um momento muito específico e delicado, uma vez que o surto psicótico toma de assalto tanto as condições psíquicas do paciente quanto as daqueles que o circundam, desde familiares mais próximos até amigos e vizinhos. Com tal consideração, passamos a notar a complexidade do desafio imposto pelo surto psicótico, pois este não tem efeitos somente na "organização psíquica" do paciente, mas põe à prova os recursos afetivos e mentais de todas as pessoas à sua volta, o que requer uma atenção clínica a aspectos ampliados da vida social e mental do paciente e sua família.

Para abordar tais meandros da clínica das patologias graves e a possibilidade, senão necessidade, de sua organização em alianças de trabalho, passaremos àquelas que só por força do hábito denominamos considerações finais, mas que, de fato, constituemse em considerações iniciais sobre um aprimoramento clínico rumo à parceria e à interdisciplinaridade.

\section{Considerações Finais}

O acompanhamento terapêutico e a psicoterapia são dois trabalhos bem diferentes e, quando 
agregados, geralmente constituem uma novidade, tanto para os pacientes quanto para os profissionais envolvidos na nova relação terapêutica formada que deixa de ser dual e passa a configurar-se como um trio composto pelo paciente, pelo psicoterapeuta e pelo acompanhante terapêutico.

Os recursos técnicos são distintos, mas, em nosso caso, ambos os profissionais trabalham com o método psicanalítico. Diferenças como o uso do setting, contato com familiares, horários etc. foram assimiladas ao longo dos atendimentos e sustentaram-se por meio do vínculo transferencial particular estabelecido com cada psicoterapeuta. Questões relativas às peculiaridades técnicas de cada modo de intervenção e às posturas de cada profissional salientam um aspecto importante da formação de uma aliança de trabalho. Deve haver o respeito ao trabalho desempenhado pelo colega, pois, para a aliança consolidar-se como tal e ultrapassar a condição de multidisciplinaridade, efetivando-se como interdisciplinaridade, é necessário o compromisso com um projeto terapêutico capaz de assimilar e usufruir a diferença constituída.

O projeto terapêutico de Renato foi sendo alterado segundo as imposições de seu quadro clínico. $O$ ingresso da dupla analítica no "impasse necessário" foi trabalhado como forma de potencializar os recursos psicoterapêuticos necessários ao paciente - naquele momento de ameaça de morte e falência dos cuidados familiares. O ingresso do AT e a formação da aliança de trabalho tiveram como ponto de apoio, para seu início e manutenção, uma relação de colaboração dos profissionais envolvidos.

Ao longo dos atendimentos, a aliança fortaleceuse junto a discussões contínuas sobre o andamento do paciente, o que nos fornecia uma visão ampliada de sua condição psíquica, do seu ambiente familiar e da assimilação do trabalho em desenvolvimento.

Ainda que possamos explorar extensamente as questões relativas à constituição do projeto terapêutico de Renato e ao modo como foi realizado o trabalho entre nós e também junto à família, retomaremos nosso objetivo inicial, a formação de uma aliança de trabalho entre psicoterapia psicanalítica e acompanhamento terapêutico. Esperamos que o tema acima possa ser objeto de uma nova e vindoura comunicação. Passaremos agora ao modo como nossa aliança teve efeito sobre quem dela mais necessitava, o paciente.

Notamos que Renato reconheceu diferentes aspectos de sua vida sendo cuidados por duas pessoas diferentes. Os atendimentos clínicos puderam ser retomados rotineiramente, em um número menor de sessões semanais, dando oportunidade à dupla e, especialmente a Renato, de vivenciar a continência afetiva de sua psicoterapeuta - que não contra-atuou os ataques por ele efetuados. Com essa retomada paulatina, foi possível a reconstrução de um vínculo que resistiu aos objetos maus e ao intenso ódio vivido pela dupla quando da crise psicótica.

Com os acompanhamentos terapêuticos, Renato pôde contar com a presença de uma companhia disposta a estar com ele, mergulhando em seu universo mental e social, ocupando em parceria os espaços do seu cotidiano. Acompanhá-lo nesses universos propiciou um contato protegido, mediado pelo AT, com os objetos constituintes de sua vida, funcionando como uma espécie de ego auxiliar - função essa que deve ser temporária, perdurando somente até a recuperação das condições egóicas mínimas do paciente.

Durante o tratamento de Renato, que contou com reformulações em seu projeto terapêutico, notamos ter sido em meio à transferência que o sentido vivo do paciente pôde ser apreendido e em meio à turbulência do surto houve o ingresso no impasse necessário. Tais movimentos, dados sob o tempo médio do processo psicoterapêutico, revelam uma postura clínica realista e inovadora, capaz de criar uma aliança de trabalho adequada às exigências daquele momento crítico, tanto para o paciente, quanto para a família e a psicoterapeuta. Tal postura termina por reverberar em efeitos terapêuticos visíveis no tempo longo do processo, tempo de uma vida, tempo do destino do paciente e sua família.

Em meio à confusão e angústia provocadas pelo surto psicótico, oferecer um acolhimento singular e extensivo ao sofrimento desse adolescente e ao de sua família consistiu no cuidado sério e atento a uma situação objetiva de perigo à integridade física e mental de Renato.

De diferentes modos, em diferentes vínculos, o trio descobriu uma modalidade de relação capaz de superar o impasse necessário, de propiciar uma contenção afetiva e mental para o período de crise, dando margem à possibilidade de juntos buscarem formas de dar corpo às fantasias, criando brincadeiras e diálogos cujas regras e sentidos fossem comunicados, pensados e não somente atuados, somando assim, esforços clínicos na mesma direção: a promoção da qualidade de saúde mental, fruto de uma aliança de trabalho proveitosa a nós, ao paciente e à sua família. 
Helga de Souza Machado Quagliatto Av. Amazonas, 2245-Jardim Umuarama - Uberlândia-MG. CEP: $38405.302-$ Tel.:(034) 3232-0664/3232-9593. E-mail:hquagliatto@bol.com.br

Ricardo Gomides Santos R. Modesta Cândida Pereira, 64 - Jardim Brasília - Uberlândia - MG CEP: 38401-380 - Tel. : (034) 3219-1404. E-mail: ricardo_gomides@yahoo.com.br

ALVAREZ, A. Companhia Viva: Psicoterapia Psicanalítica com Crianças Autistas, Borderline, Carentes e Maltratadas. Porto Alegre: Artes Médicas Sul,1994

BION, W. R. Diferenciação Entre a Personalidade Psicótica e a Personalidade Não-psicótica". In Estudos Psicanalíticos Revisados. Rio de Janeiro: Imago, 1988.

CARROZZO, N. A República-Uma Moradia Terapêutica. In Cauchick, Maria Paula. Sorrisos Inocentes, Gargalhadas Horripilantes: Intervenções no Acompanhamento Terapêutico. São Paulo: Annablume,2001.

CASSORLA ,R.M.S. Psicanálise e Surto Psicótico: Considerações Sobre Aspectos Técnicos. In Revista Brasileira de Psicanálise. v. 32 (4)1998, pp. 721-745.

HERRMANN, F. A Cura. In Jornal de Psicanálise. São Paulo, 33 (60/61), 2000, pp.425-442.

Clínica Psicanalítica: a Arte da Interpretação. 2. ed. São Paulo: Ed. Brasiliense,1993.
KLEIN, M. Os Progressos da Psicanálise. Rio de Janeiro: Zahar,1982.

MAUER, S. K. de. \& RESNIZKY, S. Acompanhantes Terapêuticos e Pacientes Psicóticos: Manual Introdutório a uma Estratégia Clínica. Campinas: Papirus, 1987.

ROUSTANG, F. Um Destino Tão Funesto. São Paulo: Ed. Taurus,1987.

SEGAL, H. (1982). Uma Abordagem Psicanalítica do Tratamento das Psicoses. In A Obra de Hanna Segal: uma Abordagem Kleiniana à Prática Clínica. Rio de Janeiro: Imago, 1982.

WINNICOTT, D. W. O Ódio na Contratransferência. In Textos Selecionados: da Pediatria à Psicanálise. 2. ed., Rio de Janeiro: Francisco Alves, 1982 .

ZIMERMAN, D. E. Patologias Graves: Aspectos Técnicos. In Revista Brasileira de Psicanálise. v. 32 (4), 1998, pp.747-761.

Fundamentos Psicanalíticos: Teoria, Técnica e Clínica - uma Abordagem Didática. Porto Alegre: Artmed,1999. 